\title{
Diversity of bacteria and mycobacteria in biofilms of two urban drinking water distribution systems
}

\author{
Ruyin Liu, Zhisheng Yu, Hongxun Zhang, Min Yang, Baoyou Shi, and Xinchun Liu
}

\begin{abstract}
In this study, to give insight into the bacterial diversity of biofilms from full-scale drinking water distribution systems (DWDSs), the bacterial community compositions of biofilms from two urban DWDSs (Guangzhou and Beijing, China) were determined using a 16S rRNA gene library technique. Meanwhile, the occurrence and diversity of mycobacteria were also analyzed by a Mycobacterium-specific $h s p$ gene assay. The biofilms from the full-scale DWDSs have complex bacterial populations. Proteobacteria was the common and predominant group in all biofilm samples, in agreement with previous reports. The community structures of bacteria at the three sites in Guangzhou DWDS were significantly different, despite the similar physicochemical properties of portable water. Some abundant and peculiar bacterial phylotypes were noteworthy, including Methylophilus, Massilia, and Planomicrobium, members of which are rarely found in DWDSs and their roles in DWDS biofilms are still unclear. The diversity of Mycobacterium species in biofilm samples was rather low. Mycobacterium arupense and Mycobacterium gordonae were the primary Mycobacterium species in Guangzhou and Beijing biofilms, respectively, indicating that $M$. arupense may be more resistant to chloride than $M$. gordonae.
\end{abstract}

Key words: biofilm, drinking water distribution systems, bacterial diversity, mycobacteria.

Résumé : Afin d'avoir un aperçu de la diversité bactérienne des biofilms présents dans un système de distribution d'eau potable de grande envergure, la composition des communautés bactériennes des biofilms obtenus de deux systèmes urbains de distribution d'eau potable (Guangzhou et Beijing, en Chine) a été déterminée par l'analyse de banques d'ARNr 16S. Simultanément, l'occurrence et la diversité des mycobactéries ont aussi été analysées à l'aide d'un test spécifique à Mycobacterium basé sur le gène hsp. Les biofilms des systèmes de distribution d'eau potable de grande envergure comprenaient des populations bactériennes complexes. Le groupe des Proteobacteriaa était le plus commun et prédominant dans tous les échantillons de biofilms, ce qui est en accord avec les rapports précédents. Les structures des communautés de bactéries de trois sites de distribution à Guangzhou étaient significativement différentes, malgré la similarité des propriétés physicochimiques de l'eau potable. Quelques phylotypes abondants et particuliers étaient à souligner, notamment, Methylophilus, Massilia et Planomicrobium, dont les membres sont rarement trouvés dans les systèmes de distribution d'eau potable, et dont le rôle dans les biofilms de ces systèmes n'est encore pas clair. La diversité d'espèces de Mycobacterium des échantillons de biofilms était relativement faible. Mycobacterium arupense et Mycobacterium gordonae constituaient les principales espèces de Mycobacterium trouvées dans les biofilms de Guangzhou et de Beijing, respectivement, indiquant que M. arupense pourrait être plus résistant au chlore que M. gordonae.

Mots-clés : biofilm, système de distribution d'eau potable, diversité bactérienne, mycobactéries.

[Traduit par la Rédaction]

\section{Introduction}

Even in the event of administering multibarrier treatment processes, it is not possible to remove all microorganisms from source water. Meanwhile, treatment failures and pipe contamination may often lead to microbial growth in drinking water distribution systems (DWDSs) (Reynolds et al. 2008). Because attached cells have certain advantages over planktonic cells, e.g., the ability to metabolize recalcitrant organic compounds (Berry et al. 2006) and increased resistance to chlorine (Emtiazi et al. 2004; Tachikawa et al. 2005), bio- films predominate in DWDSs and cause many public health issues, such as protecting and supporting pathogenic microorganisms (Buswell et al. 1998), bacterial regrowth (LeChevallier et al. 1991), and depletion of disinfection agents (Regan et al. 2002). Therefore, many researchers have focused on biofilms in DWDSs.

Due to limited access and the high cost involved in sampling, current information on the microbial diversity of biofilm within full-scale DWDSs is still scant. Several studies have used model DWDSs and removable coupons for biofilm attachment inserted (for short times) in real DWDSs (Berry et

Received 26 September 2011. Revision received 19 November 2011. Accepted 23 November 2011. Published at

www.nrcresearchpress.com/cjm on 22 February 2012.

R. Liu, Z. Yu, H. Zhang, and X. Liu. College of Environmental and Resource Sciences, Graduate University of Chinese Academy of Sciences, 100049 Beijing, People's Republic of China.

M. Yang and B. Shi. Research Centre for Eco-Environmental Sciences, Chinese Academy of Sciences, Beijing 100085, People's Republic of China.

Corresponding author: Zhisheng Yu (e-mail: yuzs@gucas.ac.cn). 
al. 2006). However, because the formation of a biofilm is the result of successional development into a mature community, it may require several years before steady state is achieved, which limits the relevance of short-term model studies (Martiny et al. 2003). The characterization of microbial communities of biofilms in full-scale DWDSs is far from being understood in detail.

Nontuberculous mycobacteria (NTM) have been frequently found in DWDSs, and members of them are reported as opportunistic pathogens (September et al. 2004; Vaerewijck et al. 2005). Infections with NTM are usually restricted to immunocompromised patients or persons with underlying diseases, while some also infect healthy people (Graham 2002). Because mycobacteria are generally tolerant to disinfects, they can form biofilms on the surface of pipelines (HallStoodley et al. 1998; Szewzyk et al. 2000), characters of which make them more difficult to eliminate from DWDSs (Hall-Stoodley et al. 1998). Their growth in DWDSs may constitute a risk to consumers by drinking water or inhalation of aerosols while showering (Feazel et al. 2009).

In this study, to characterize bacterial diversity in biofilm from full-scale DWDSs, the bacterial community structures in biofilms of two urban DWDSs (Guangzhou and Beijing, China) were revealed by cloning and sequencing of polymerase chain reaction (PCR)-amplified 16S rRNA gene fragments. Meanwhile, for understanding the potential health risk of NTM in the DWDSs, the occurrence and diversity of mycobacteria in the biofilms were also investigated by using a Mycobacterium-specific PCR method.

\section{Materials and methods}

\section{Sample collection and DNA extraction}

Five polyvinyl chloride (PVC) pipe sections were collected from three sampling sites (A, B, and C) in the same distribution system in Guangzhou in June 2010. Two pipe sections were taken from each point B and C. In the same month, one PVC pipe section was obtained from Beijing. Immediately after collection, samples were transported to our lab and stored at $4{ }^{\circ} \mathrm{C}$. Water samples $(10 \mathrm{~L})$ were collected from each sampling site for water quality analysis. The water quality parameters analyzed and values are listed (Table 1).

Approximately $2.0 \mathrm{~cm}^{2}$ of biofilm samples were scraped using sterile spatulas. Then, the samples were washed three times using aseptic phosphate-buffered saline $(\mathrm{pH}$ 7.0) and centrifugation at $10000 \mathrm{r} \cdot \mathrm{min}^{-1}(10400 \mathrm{~g})$ at $4{ }^{\circ} \mathrm{C}$ for 15 min. After centrifugation, DNA was extracted using a FastDNA spin kit for soil (Qbiogene, Solon, Ohio) facilitated with the FastPrep-24 bead beater system, following the manufacturer's instructions, and then quantified with a Nanodrop 1000 spectrophotometer (Thermo Scientific, Wilmington, Delaware).

\section{Cloning and sequencing}

The bacterial $16 \mathrm{~S}$ rRNA gene fragments were amplified by PCR using primers 27F (5'-AGAGTTTGATCCTGGCTCAG$\left.3^{\prime}\right)$ and 1492R (5'-GACGGGCGGTGTGTAC-3'). The partial heat shock protein $(h s p)$ gene sequences of mycobacteria were amplified using primers HspF (5'-CTGGTCAAGGAAGGTCTGCG-3') and HspR (5'-GATGACACCCTCGTTGCCAAC-3') (Khan and Yadav 2004). The PCR conditions for

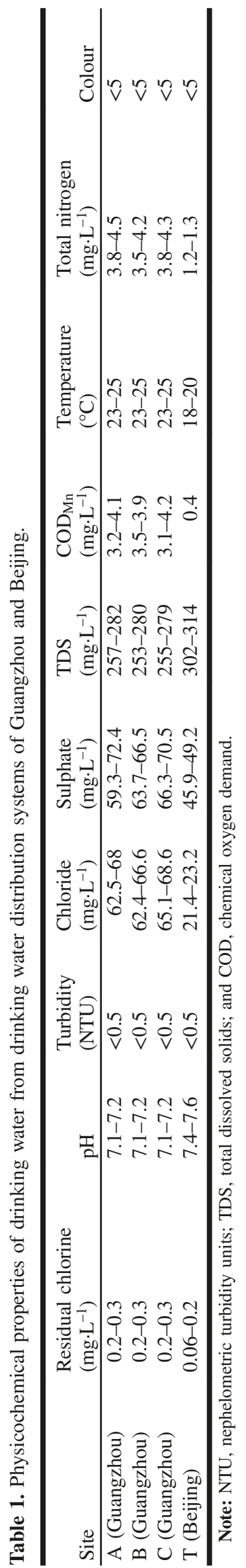

Published by NRC Research Press 
Fig. 1. Principal components analysis performed using UniFrac metric based on all 16S rRNA gene sequences from biofilms in Guangzhou and Beijing drinking water distribution systems shown on the left (Components 1 represents 16S rRNA gene sequences and Components 2 represents sampling sites), with bacterial community clustering using the thetayc calculator of MOTHUR software shown on the right. Capitals in parentheses represent sampling sites (A, B, and $\mathrm{C}$ are from Guangzhou and $\mathrm{T}$ is from Beijing).

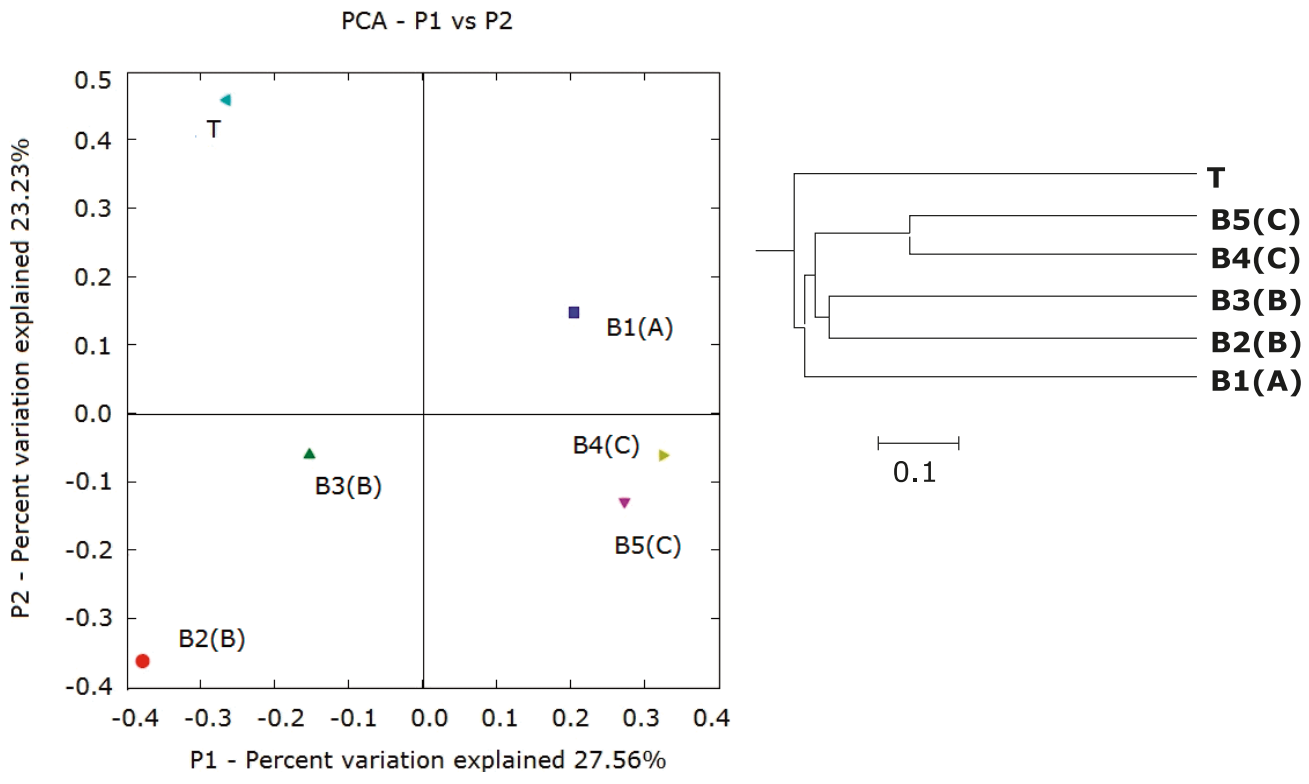

the amplification of the bacterial 16S rRNA gene were as follows: $95{ }^{\circ} \mathrm{C}$ for $10 \mathrm{~min}$, followed by 30 cycles of $95{ }^{\circ} \mathrm{C}$ for $1 \mathrm{~min}, 55^{\circ} \mathrm{C}$ for $1 \mathrm{~min}$, and $72{ }^{\circ} \mathrm{C}$ for $1 \mathrm{~min}$ and $30 \mathrm{~s}$, and a final extension at $72{ }^{\circ} \mathrm{C}$ for $10 \mathrm{~min}$. For amplification of the $h s p$ gene, the PCR conditions were $95{ }^{\circ} \mathrm{C}$ for $10 \mathrm{~min}$, followed by 30 cycles of $95{ }^{\circ} \mathrm{C}$ for $15 \mathrm{~s}, 58{ }^{\circ} \mathrm{C}$ for $15 \mathrm{~s}$, and $72{ }^{\circ} \mathrm{C}$ for $30 \mathrm{~s}$, and a final extension at $72{ }^{\circ} \mathrm{C}$ for $10 \mathrm{~min}$. PCR products were confirmed by electrophoresis in $1.2 \%$ agarose gel.

Three separate reactions for the bacterial 16S rRNA gene and the hsp gene of mycobacteria were run for each sample to minimize PCR bias in subsequent cloning steps, and all relevant PCR products from the same sample were further pooled together. The amplification products were purified with a QIAquick PCR cleanup kit (Qiagen, Inc., Chatsworth, California) and cloned into the TOPO TA cloning vector pCR2.1, and then TOP10 chemically competent Escherichia coli was transformed with the plasmids in accordance with the manufacturer's instructions (Invitrogen). Transformants were selected by blue-white selection on Luria-Bertani agar plates containing ampicillin $\left(100 \mathrm{mg} \cdot \mathrm{mL}^{-1}\right)$. Cloned inserts were amplified from lysed colonies by PCR with plasmidvector specific primers M13F (5'-GTAAAACGACGGCCAG-3') and M13R (5'-CAGGAAACAGCTATGAC-3'). Clones were sequenced with an ABI 3730 automated sequencer (Invitrogen, Shanghai, China).

\section{Phylogenetic analysis}

Sequences were searched against the Ribosomal Database Project II (RDP II) release 9.49 and the GenBank database by using the BLASTn program to determine the closest matches. Possible chimeras were checked with Bellerophon version 3 (http://greengenes.lbl.gov/cgi-bin/nph-bel3_interface.cgi). Phylogenetic trees were constructed using MEGA version 4.0 by the neighbor-joining algorithm, and the Jukes-Cantor dis- tance estimation method with bootstrap analyses for 1000 replicates was performed. The operational taxonomic unit (OTU) number was determined using MOTHUR by defining the sequences sharing $97 \%$ similarity as 1 OTU. Shannon diversity indices $(H)$ were also calculated using MOTHUR. Evenness $(E)$ indices were calculated as follows: $E=H / \ln n$, where $n$ is the number of OTUs. Coverage $(C)$ was calculated as follows: $C=1-\left(n_{l} / N\right)$, where $n_{l}$ is the number of OTUs that occurred once and $N$ is the total number of clones (Singleton et al. 2001). UniFrac computational analysis was performed to compare clone libraries from different sampling sites.

\section{Nucleotide sequence accession numbers}

The partial 16S rRNA gene and $h s p$ gene sequences that were determined have been deposited in GenBank nucleotide sequence databases under accession Nos. JF922382JF922605 and JN628293-JN628434.

\section{Results}

\section{Physicochemical properties}

As shown in Table 1, the physicochemical properties of water from three sampling sites in Guangzhou were similar. However, the temperature, chemical oxygen demand (COD), total dissolved solids (TDS), total nitrogen, and concentrations of chloride and sulphate in water from Guangzhou were markedly higher than those in water from Beijing.

\section{Bacterial community in DWDS biofilms}

Six clone libraries of $16 \mathrm{~S}$ rRNA genes were, respectively, constructed for the biofilm samples collected from Guangzhou (B1, B2, B3, B4, and B5) and Beijing (T) DWDSs. The five Guangzhou biofilm samples were taken from the three following points: B1 from point A; B2 and B3 from point B; and B4 and B5 from point C. A total of 270 sequen- 
Table 2. Distribution of phylogenetic groups among bacterial 16S rRNA gene clone libraries for five Guangzhou biofilm samples and one Beijing biofilm sample.

\begin{tabular}{|c|c|c|c|c|c|c|c|c|c|c|}
\hline \multirow[b]{2}{*}{ Phylum } & \multirow[b]{2}{*}{ Class } & \multirow[b]{2}{*}{ Order } & \multirow[b]{2}{*}{ Family } & \multirow[b]{2}{*}{ Genus } & \multicolumn{6}{|c|}{ No. of OTUs (no. of clones) ${ }^{a}$} \\
\hline & & & & & $\mathrm{B} 1(\mathrm{~A})$ & $\mathrm{B} 2(\mathrm{~B})$ & $\mathrm{B} 3(\mathrm{~B})$ & $\mathrm{B} 4(\mathrm{C})$ & $\mathrm{B} 5(\mathrm{C})$ & $\mathrm{T}$ \\
\hline \multirow[t]{32}{*}{ Proteobacteria } & Alphaproteobacteria & Caulobacterales & Caulobacteraceae & Brevundimonas & $1(2)$ & & & $2(6)$ & $2(3)$ & \\
\hline & & Rhodospirillales & Unclassified & & & $2(2)$ & & & & \\
\hline & & Sphingomonadales & Sphingomonadaceae & Sphingomonas & & & & & & $4(16)$ \\
\hline & & & & Sphingobium & & $2(8)$ & $3(24)$ & & $1(2)$ & $1(2)$ \\
\hline & & & & Novosphingobium & & & & & $1(1)$ & $3(4)$ \\
\hline & & & & Sphingopyxis & & & $1(1)$ & & & $1(1)$ \\
\hline & & & & Unclassified & & & & $1(1)$ & & $1(4)$ \\
\hline & & Rhizobiales & Bradyrhizobiaceae & Bradyrhizobium & & & & & & $2(4)$ \\
\hline & & & & Unclassified & & & & & & $1(2)$ \\
\hline & & & Hyphomicrobiaceae & Rhodoplanes & & $1(1)$ & $1(1)$ & & $1(1)$ & \\
\hline & & & & Hyphomicrobium & & $1(1)$ & & & & $1(1)$ \\
\hline & & & Unclassified & & & & & & $1(1)$ & $1(3)$ \\
\hline & & Unclassified & & & & $1(1)$ & & & & $1(2)$ \\
\hline & Betaproteobacteria & Methylophilales & Methylophilaceae & Methylophilus & $2(20)$ & & & & & \\
\hline & & & & Unclassified & $1(13)$ & & & & & \\
\hline & & Nitrosomonadales & Nitrosomonadaceae & Unclassified & & & & & & $1(1)$ \\
\hline & & Burkholderiales & Comamonadaceae & Acidovorax & & & $1(5)$ & & $1(1)$ & \\
\hline & & & & Delftia & & & & $1(2)$ & & \\
\hline & & & & Comamonas & & $1(1)$ & & & & \\
\hline & & & & Pelomonas & & $1(1)$ & & & & \\
\hline & & & Oxalobacteraceae & Massilia & & & & $1(22)$ & $2(3)$ & \\
\hline & & & & Unclassified & & & & $1(3)$ & $1(1)$ & \\
\hline & & & Alcaligenaceae & Derxia & & & & $1(1)$ & & \\
\hline & & & Unclassified & & & $2(4)$ & $1(2)$ & $2(2)$ & 1(2) & \\
\hline & & Unclassified & & & $1(1)$ & & $2(2)$ & & 2(2) & \\
\hline & Gammaproteobacteria & Chromatiales & Chromatiaceae & Rheinheimera & 2(3) & & & & & \\
\hline & & Pseudomonadales & Moraxellaceae & Acinetobacter & $1(1)$ & & & & & \\
\hline & & Xanthomonadales & Xanthomonadaceae & Lysobacter & & & & $1(1)$ & $1(1)$ & \\
\hline & & Unclassified & & & & & & 1(1) & $1(3)$ & $1(1)$ \\
\hline & Deltaproteobacteria & Myxococcales & Cystobacterineae & Unclassified & & $1(1)$ & & & & \\
\hline & & & Nannocystineae & Haliangium & & $1(1)$ & & & & \\
\hline & & Unclassified & & & $1(1)$ & & & $1(2)$ & $1(1)$ & \\
\hline \multirow[t]{4}{*}{ Firmicutes } & Bacilli & Bacillales & Bacillaceae & Bacillus & & & $1(1)$ & & & \\
\hline & & & & Exiguobacterium & $1(2)$ & & $1(1)$ & & & \\
\hline & & & Planococcaceae & Planomicrobium & & & & $1(2)$ & $2(12)$ & \\
\hline & & & Unclassified & & 1(3) & & & & & \\
\hline \multirow[t]{2}{*}{ Chloroflexi } & Anaerolineae & Anaerolineales & Anaerolineaceae & Unclassified & & & & & $1(1)$ & \\
\hline & Unclassified & & & & & $2(2)$ & $1(1)$ & $1(1)$ & $1(1)$ & \\
\hline \multirow[t]{3}{*}{ Actinobacteria } & Rubrobacteridae & Solirubrobacterales & Conexibacteraceae & Conexibacter & $1(1)$ & & & & 1(1) & \\
\hline & & & Unclassified & & & & $1(1)$ & & $1(1)$ & \\
\hline & Acidimicrobidae & Acidimicrobiales & Acidimicrobineae & Unclassified & & & & & $1(1)$ & \\
\hline
\end{tabular}


ces were obtained and grouped into 98 OTUs with a sequence similarity of 0.97 , using MOTHUR software. Possible chimeras were discarded. MOTHUR analysis indicated that five Guangzhou bacterial communities were more similar to one another as compared with the control Beijing bacterial community, and bacterial communities from the same sampling site showed more similarity (Fig. 1). Principal component analysis by UniFrac also showed similar results (Fig. 1).

In the six biofilm libraries, the phylum Proteobacteria was the predominant group. Of those, Alphaproteobacteria and Betaproteobacteria were found in all six biofilm samples. Other classified taxonomic groups in DWDS biofilm samples included Firmicutes, Chloroflexi, Actinobacteria, Planctomycetes, Nitrospira, Acidobacteria, and Verrucomicrobia (Table 2; Fig. 2).

Among clone sequences derived from the biofilm sample in the Beijing DWDS, the majority (89.1\%) were affiliated with the phylum Proteobacteria including Alphaproteobacteria (84.8\%), Betaproteobacteria, and Gammaproteobacteria, followed by the phyla Nitrospira (8.7\%) and Acidobacteria (3.1\%) (Table 2). In the Proteobacteria, a number of sequences were assigned to the family Sphingomonadaceae in $\mathrm{Al}$ phaproteobacteria, within which the bacterial genera identified were generally residents in biofilms or DWDSs. One clone (T-65) showed high similarity (97\%) with ammonia-oxidizing Nitrosomonas sp. strain Nm86 (accession No. AY123798.1). Four clones were assigned to the genus Nitrospira, members of which had an autotrophic metabolism using nitrite as an electron donor.

Most of the sequences from point A (67.3\%) were assigned to the family Methylophilaceae (Table 2) and showed homology with Methylophilus spp., Methylotenera spp., and Methylobacillus spp. Deltaproteobacteria clone B1-41 and Actinobacteria clone B1-21 were closely related to those retrieved from biofilms. Other clones in the B1 library were related to some heterotrophic bacteria in Firmicutes and Gammaproteobacteria. In the B2 and B3 clone libraries constructed from two biofilm samples at point B, many sequences were similar to those derived from soil or freshwater sediments. Similar to the Beijing biofilm community, Alphaproteobacteria sequences were abundant $(30.2 \%$ and $56.5 \%$, respectively) in the $\mathrm{B} 2$ and $\mathrm{B} 3$ libraries, while the bacterial genera were not so diverse, and most of those belonged to the genus Sphingobium (18.6\% and 52.2\%, respectively). Other Proteobacteria sequences from site B were mainly assigned within the order Burkholderiales in Betaprotobacteria. Bacteria in the phylum Acidobacteria encompassed $18.6 \%$ of the B2 sequenced clones $(4.3 \%$ clones in B3 library). There was one clone in the B3 library (B3-52) that showed high similarity (99\%) to nitrite-oxidizing bacterium Nitrospira defluvii (accession No. FP929003). For the two biofilm bacterial communities (B4 and B5) from sampling point $\mathrm{C}$, individually 25 (50\% of B4 clones) and four clone sequences of the B4 and B5 libraries were grouped into the family Oxalobacteraceae in Betaprotobacteria, and most of those showed close similarities (97\%-99\%) to Massilia aurea (accession No. AM231588), which was originally isolated from the drinking water distribution system of Seville (Spain). In addition, a number of clone sequences in B5 library $(28.6 \%)$ were closely related to Planomicrobium spp. (Table 2). 
Fig. 2. Richness and abundance distribution of bacterial populations in Guangzhou and Beijing biofilm samples. A, B, and C are from Guangzhou and $\mathrm{T}$ is from Beijing.

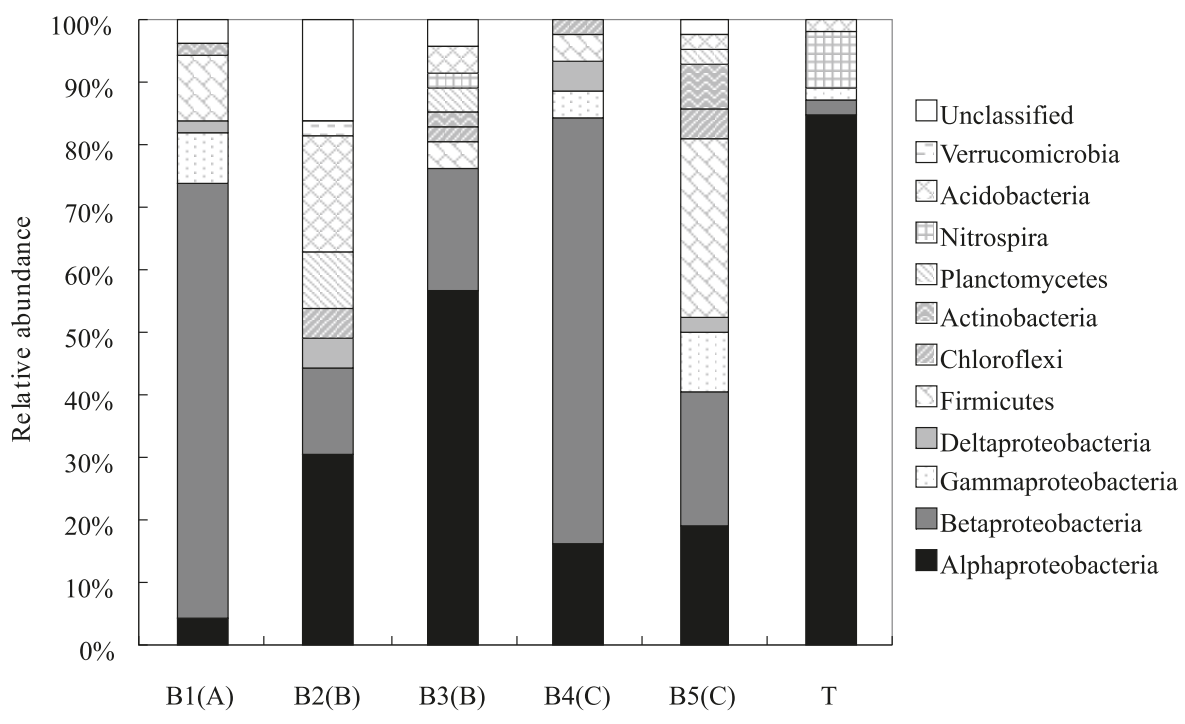

Table 3. Coverage and diversity indices of bacterial 16S rRNA gene libraries for biofilm samples in drinking water distribution systems.

\begin{tabular}{lllllll}
\hline & B1(A) & B2(B) & B3(B) & B4(C) & B5(C) & T \\
\hline Shannon index & 2.39 & 3.83 & 2.84 & 2.27 & 3.66 & 3.02 \\
No. of clones & 49 & 43 & 46 & 44 & 42 & 46 \\
No. of OTUs & 14 & 28 & 20 & 14 & 26 & 20 \\
Coverage (\%) & 85.7 & 44.2 & 65.2 & 81.8 & 52.4 & 78.3 \\
Richness & 0.905 & 1.148 & 0.946 & 0.861 & 1.123 & 1.007 \\
\hline
\end{tabular}

Note: Capital letters in parentheses represent sampling sites (A, B, and C are from Guangzhou and $\mathrm{T}$ is from Beijing). OTU, operational taxonomic unit.

\section{Bacterial diversity}

As shown in Table 3, Shannon diversity indices for all biofilm samples ranged from 2.27 to 3.83 , the values of which were comparable with some derived from river water or even soil, indicating that the bacterial species diversities were high in the biofilms of DWDSs (Table 2). Furthermore, although drinking water from the three sampling sites of Guangzhou have similar physical and chemical properties (Table 1), biofilm bacterial community structures were significantly different from each other (based on LIBSHUFF analysis, data not shown), and none of the biofilm OTUs were shared by all of the three points. Microbial community diversity may affect disinfection efficacy and pathogen survival. A study with a flow cell system showed that multispecies biofilms were more resistant to biocides than single-species biofilms (Elvers et al. 2002).

\section{Mycobacteria in DWDS biofilms}

A pair of genus-specific primers was employed to amplify the heat shock protein ( $h s p$ ) gene of Mycobacterium spp. PCR products from DNA extracted from all biofilm samples showed the expected $\sim 228 \mathrm{bp}$ PCR fragments, and a total of 96 hsp gene clones were obtained.

The majority of $h s p$ gene sequences (81 of 84 sequences) from the five Guangzhou biofilms showed high similarities
(97\%-99\%) to Mycobacterium arupense (Fig. 3), while most of the sequences from the Beijing biofilm (15 of 16 sequences) showed high homology to (98\%-99\%) Mycobacterium gordonae. Mycobacterium gordonae may cause nosocomial pulmonary and systemic infections in the elderly (Saeki et al. 2004) and the immunosuppressed. It has been isolated from surface water, municipal water supplies, and biofilms from DWDSs (September et al. 2004). Mycobacterium arupense is a novel and potentially pathogenic Mycobacterium species, which has been isolated from human clinical samples (Neonakis et al. 2010), small terrestrial mammals, and surface water (Slany et al. 2010). It was reported that M. arupense causes tenosynovitis in a patient with diabetes mellitus (Tsai et al. 2008). Meanwhile, one clone (Myco-B2-11) showed high similarity (98\%) to Mycobacterium immunogenum (accession No. DQ288262), which may lead to hypersensitivity pneumonitis (World Health Organization 2006). In addition, as shown in Fig. 3, two clones (Myco-B5-6 and Myco-T28) form a separate group, phylogenetically distinct with $M$. arupense and other known Mycobacterium species. Microorganisms represented by them might be new Mycobacterium species. Of those, clone Myco-B5-6 showed high similarity (99\%) to Mycobacterium sp. strain FI-07153 (accession No. EU370530.1) isolated from clinical specimens. 
Fig. 3. Phylogenetic analysis of hsp gene sequences of Mycobacterium spp. retrieved from biofilms in drinking water distribution systems determined by the neighbor-joining method. Bootstrap values $>50 \%$ (obtained with 1000 resamplings) are shown at the nodes. The scale bar represents 0.01 nucleotide substitutions per site. Numbers in parentheses represent the sequence accession numbers in GenBank. The contents in square brackets indicate the $h s p$ gene clone number in different libraries. In the name of $h s p$ gene clone sequence, e.g., Myco-B2-11, Myco represents Mycobacterium and B2 represents the clone derived from the B2 biofilm sample.

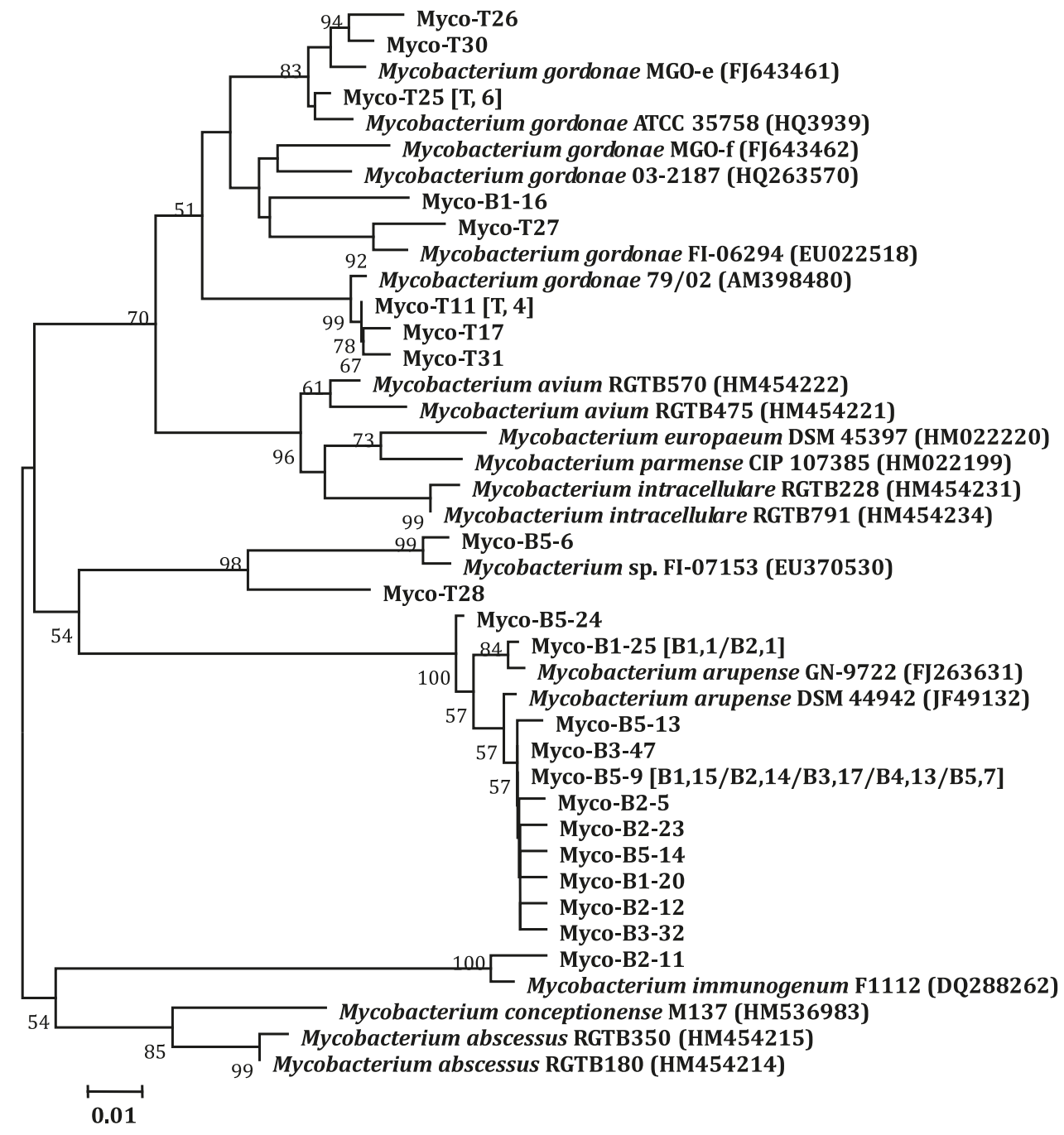

\section{Discussion}

As we expected, principal component analysis and clustering analysis for the clone libraries using Unifrac and MOTHUR software indicated that biofilms from the same sampling point, i.e., B2 and B3 from point B and B4 and B5 from point $\mathrm{C}$, possessed similar community structures of bacteria compared with the others. LIBSHUFF analysis further demonstrated that there was no significant difference between bacterial communities from the same site. This indicated that the small clone libraries can still effectively display differences and similarities between microbial communities in combination with statistical analysis. However, it should be noted that the proportion of dominant populations within the libraries were obviously different, e.g., $56.8 \%$ and $9.5 \%$ of clone sequences classified into the genus Massilia in B4 and B5 libraries, respectively, and $18.6 \%$ and $52.2 \%$ of clone sequences identified as Sphingobium in B2 and B3 libraries, respectively (Table 2). Although some studies showed that the dominant phylogenetic groups in 16S rRNA gene clone libraries are the same as the dominant in situ groups determined by fluorescence in situ hybridization in natural microbial communities (Cary et al. 1997; Schramm et al. 1998; Ficker et al. 1999), our results suggest that estimations of the relative abundance of bacteria should be done with caution.

The bacterial community of Beijing DWDS biofilms was distinctly separated with those from Guangzhou DWDS, reflecting the influence of water quality on biofilm microbial community in DWDSs (van der Kooij 1999; Volk and LeChevallier 1999). However, bacterial communities at sites A, $\mathrm{B}$, and $\mathrm{C}$ from Guangzhou DWDS significantly differed with eachother (based on LIBSHUFF analysis) despite the similar physicochemical properties of water (Table 1) from the three points. This implies there are other environmental factors critical for biofilm formation in DWDSs, e.g., hydrodynamic characteristics. The hydraulic patterns at site $\mathrm{C}$ might vary from other sites considering the different pipe diameter $(5 \mathrm{~cm})$ with the others $(3 \mathrm{~cm})$. Manuel et al. (2007) indicated 
that hydrodynamic conditions are of great importance to the behavior of bacteria in biofilms as they affect their accumulation and detachment.

Similar to other investigations for water supply systems using molecular methods (Kalmbach et al. 2000; Schmeisser et al. 2003; Williams et al. 2004), the phylum Proteobacteria (especially Alphaproteobacteria or Betaproteobacteria) was the common and primary bacterial group in the biofilm communities from the two urban DWDSs. Within the Alphaproteobacteria, a number of Sphingomonadaceae-related sequences were retrieved from both Beijing and Guangzhou biofilms (Table 2). Many Sphingomonadaceae bacteria can produce abundant exopolysaccharides (EPS), lack special growth requirements, and are resistant to chlorine (Furuhata et al. 2007), characteristics of which conferred an ecological advantage for their growth and formation of stable biofilms in oligotrophic water environments (White et al. 1996). On the other hand, it is noteworthy that some interesting populations were found in Guangzhou biofilms. Oxalobacteraceaelike bacteria were only detected site C, comprising $56.8 \%$ of B4 clones and $9.5 \%$ of B5 clones, most of which were closely related to $M$. aurea isolated from a DWDS of Seville, Spain. The ubiquitous nature of Massilia spp. in various soil habitats implied that these bacteria may be derived from soils. Massilia bacteria were also found to be dominant $(55 \%$ of $16 \mathrm{~S}$ rRNA gene clones) in the biofilm on a surface of a corroded lead line removed from real DWDS of Illinois, USA (White et al. 2011). Some surface properties of Massilia cells could be propitious to their occurrence and growth on DWDS biofilms. Recent work with AFM force spectroscopy and physicochemical analyses indicated that the high hydrophobicity, surface charges, and great propensity to form EPS by Massilia timonae may lead to a high adhesive force on the metal surface (Harimawan et al. 2011). In addition, Planomicrobium bacteria (28.6\% of B5 clones) were also only detected at point C. It was reported that strain MAE2 of Planomicrobium was capable of extensive degradation of alkanes in crude oil (Engelhardt et al. 2001). This implies that Planomicrobium cells possibly possess high hydrophobicity, which may contribute to their adhesion on hydrophobic surfaces of PVC pipe. In contrast, members of the family Methylophilaceae (67.3\% of B1 clones) in Betaproteobacteria were only retrieved from sampling site A in Guangzhou and were mainly associated with the genus Methylophilus. There are few reports on the discovery of Methylophilaceae bacteria in DWDSs. Recently using a 454 pyrosequencing method, Hong et al. (2010) found that Methylophilus-related sequence reads were in abundance in a water metre biofilm from private households in UrbanaChampaign, Illinois, USA. Besides, it was reported that Methylophilus spp. can live in the cytoplasm of Acanthamoeba isolated from domestic tap water in Korea (Choi et al. 2009). The isolated Methylophilus bacteria are strictly aerobic, obligate methylotrophs using methanol as the growth substrate, and can form EPS (Doronina et al. 2005; Gogleva et al. 2010). Hong et al. (2010) speculated that Methylophilus spp. fed methanol produced by methanotrophs in the metre biofilm, but no methanotroph-related clone was retrieved from Guangzhou biofilm samples probably due to the small sizes of our clone libraries. Overall, it is still hard to explain the differences among the bacterial communities of Guang- zhou biofilms and the high occurrence of some special populations based on the analysis for the clone libraries and physicochemical properties of the drinking water. To address these issues, it is necessary to isolate those abundant phylotypes within the libraries from DWDS biofilms and further recognize their characteristics of biofilm formation and development. Furthermore, in addition to the routine water qualities, other environmental factors possibly associated with DWDS biofilms (e.g., hydrodynamic condition, surface property of pipe, EPS matrix, etc.) should also be considered.

NTM often occur in biofilms that form in water supply systems (Falkinham et al. 2001; Le Dantec et al. 2002a, $2002 b$ ). In this study, the Mycobacterium specific $65 \mathrm{kDa}$ heat shock protein gene, an effective target for species differentiation in mycobacteria (Khan and Yadav 2004), was used to determine the diversity of Mycobacterium species in DWDS biofilms. Unlike the bacterial communities, the diversity of Mycobacterium species was low, and there was no significant difference among Guangzhou biofilms. However, the primary Mycobacterium species in the two urban DWDS biofilms were clearly different, with $M$. arupense and $M$. gordonae in Guangzhou and Beijing, respectively. Mycobacterium gordonae is frequently found in drinking water supplies, while to our knowledge, this is the first discovery of $M$. arupense occurring in DWDS biofilms. The difference in Mycobacterium species may be correlated with the different levels of residual chlorine (Table 1). Mycobacteria are generally resistant to disinfectants due to the complex cell wall, but there are different tolerances to disinfectants among species. Previous research indicated that Mycobacterium chelonae and Mycobacterium fortuitum were more resistant, whereas Mycobacterium aurum appeared to be the most susceptible mycobacterial species to chlorine. Le Dantec et al. (2002a) calculated that chlorination at $0.5 \mathrm{mg} \cdot \mathrm{L}^{-1}$ chlorine for $2 \mathrm{~h}$ could eliminate over $4 \log$ units of $M$. gordonae, but only $1.5 \mathrm{log}$ units of $M$. fortuitum or $M$. chelonae. Considering the relatively high level of residual chlorine in water from Guangzhou, M. arupense seems more resistant to chloride than M. gordonae. On the other hand, it should be noted that the mycobacteria detected here were possibly associated with human health. Although their pathogenicity requires further research, the potential pathogenic mycobacteria in DWDSs should still arouse more authorities' attention, especially in areas with a high prevalence of immunocompromised persons.

In comparison with mycobacteria, Legionella spp. are more susceptible to residual chloride in portable water, which should be the main reason for no representatives of Legionella found in the DWDS biofilms. Though biofilm and protozoa may supply protection for Legionella, in another study using 454 pyrosequencing (unpublished data), we found that only one sequence read was related to Legionella in a total of 13351 sequences retrieved from the biofilm of a DWDS with $0.02 \mathrm{mg} \cdot \mathrm{L}^{-1}$ of free chloride, while 172 sequences were classified as Mycobacterium.

\section{Acknowledgements}

This work was funded by the Knowledge Innovation Project of Chinese Academy of Science (Y025014EA2) and the Dean Fund of Graduate University of Chinese Academy of Sciences 2011B (Y15102FN00). 


\section{References}

Berry, D., Xi, C., and Raskin, L. 2006. Microbial ecology of drinking water distribution systems. Curr. Opin. Biotechnol. 17(3): 297302. doi:10.1016/j.copbio.2006.05.007. PMID:16701992.

Buswell, C.M., Herlihy, Y.M., Lawrence, L.M., McGuiggan, J.T., Marsh, P.D., Keevil, C.W., and Leach, S.A. 1998. Extended survival and persistence of Campylobacter spp. in water and aquatic biofilms and their detection by immunofluorescentantibody and -rRNA staining. Appl. Environ. Microbiol. 64(2): 733-741. PMID:9464415.

Cary, S.C., Cottrell, M.T., Stein, S.L., Camacho, F., and Desbruyeres, D. 1997. Molecular identification and localization of filamentous symbiotic bacteria associated with the hydrothermal vent annelid Alvinella pompejana. Appl. Environ. Microbiol. 63(3): 11241130. PMID:16535543.

Choi, S.H., Cho, M.K., Ahn, S.C., Lee, J.E., Lee, J.S., Kim, D.H., et al. 2009. Endosymbionts of Acanthamoeba isolated from domestic tap water in Korea. Korean J. Parasitol. 47(4): 337-344. doi:10. 3347/kjp.2009.47.4.337. PMID:19967080.

Doronina, N., Ivanova, E., Trotsenko, Y., Pshenichnikova, A., Kalinina, E., and Shvets, V. 2005. Methylophilus quaylei sp nov., a new aerobic obligately methylotrophic bacterium. Syst. Appl. Microbiol. 28(4): 303-309. doi:10.1016/j.syapm.2005.02. 002. PMID:15997702.

Elvers, K.T., Leeming, K., and Lappin-Scott, H.M. 2002. Binary and mixed population biofilms: time-lapse image analysis and disinfection with biocides. J. Ind. Microbiol. Biotechnol. 29(6): 331-338. doi:10.1038/sj.jim.7000318. PMID:12483475.

Emtiazi, F., Schwartz, T., Marten, S.M., Krolla-Sidenstein, P., and Obst, U. 2004. Investigation of natural biofilms formed during the production of drinking water from surface water embankment filtration. Water Res. 38(5): 1197-1206. doi:10.1016/j.watres. 2003.10.056. PMID:14975653.

Engelhardt, M.A., Daly, K., Swannell, R.P.J., and Head, I.M. 2001. Isolation and characterization of a novel hydrocarbon-degrading, Gram-positive bacterium, isolated from intertidal beach sediment, and description of Planococcus alkanoclasticus sp nov. J. Appl. Microbiol. 90(2): 237-247. doi:10.1046/j.1365-2672.2001.01241. x. PMID:11168727.

Falkinham, J.O., III, Norton, C.D., and LeChevallier, M.W. 2001. Factors influencing numbers of Mycobacterium avium, Mycobacterium intracellulare, and other Mycobacteria in drinking water distribution systems. Appl. Environ. Microbiol. 67(3): 1225-1231. doi:10.1128/AEM.67.3.1225-1231.2001. PMID:11229914.

Feazel, L.M., Baumgartner, L.K., Peterson, K.L., Frank, D.N., Harris, J.K., and Pace, N.R. 2009. Opportunistic pathogens enriched in showerhead biofilms. Proc. Natl. Acad. Sci. U.S.A. 106(38): 16393-16399. doi:10.1073/pnas.0908446106. PMID:19805310.

Ficker, M., Krastel, K., Orlicky, S., and Edwards, E. 1999. Molecular characterization of a toluene-degrading methanogenic consortium. Appl. Environ. Microbiol. 65(12): 5576-5585. PMID:10584020.

Furuhata, K., Kato, Y., Goto, K., Saitou, K., Sugiyama, J., Hara, M., and Fukuyama, M. 2007. Identification of yellow-pigmented bacteria isolated from hospital tap water in Japan and their chlorine resistance. Biocontrol Sci. 12(2): 39-46. PMID:17629244.

Gogleva, A.A., Kaparullina, E.N., Doronina, N.V., and Trotsenko, Y. A. 2010. Methylophilus flavus sp. nov., and Methylophilus luteus sp. nov., aerobic, methylotrophic bacteria associated with plants. Int. J. Syst. Evol. Microbiol. 60(11): 2623-2628. doi:10.1099/ijs.0. 019455-0. PMID:20023062.

Graham, D.R. 2002. Hot-tub-associated mycobacterial infections in immunosuppressed persons. Emerg. Infect. Dis. 8(7): 750. PMID: 12095454.

Hall-Stoodley, L., Keevil, C.W., and Lappin-Scott, H.M. 1998.
Mycobacterium fortuitum and Mycobacterium chelonae biofilm formation under high and low nutrient conditions. J. Appl. Microbiol. 85(Suppl. 1): 60S-69S. doi:10.1111/j.1365-2672. 1998.tb05284.x. PMID:21182694.

Harimawan, A., Rajasekar, A., and Ting, Y.P. 2011. Bacteria attachment to surfaces - AFM force spectroscopy and physicochemical analyses. J. Colloid Interface Sci. 364(1): 213-218. doi:10.1016/j.jcis.2011.08.021. PMID:21889162.

Hong, P.-Y., Hwang, C., Ling, F., Andersen, G.L., LeChevallier, M. W., and Liu, W.-T. 2010. Pyrosequencing analysis of bacterial biofilm communities in water meters of a drinking water distribution system. Appl. Environ. Microbiol. 76(16): 56315635. doi:10.1128/AEM.00281-10. PMID:20581188.

Kalmbach, S., Manz, W., Bendinger, B., and Szewzyk, U. 2000. In situ probing reveals Aquabacterium commune as a widespread and highly abundant bacterial species in drinking water biofilms. Water Res. 34(2): 575-581. doi:10.1016/S0043-1354(99)00179-7.

Khan, I.U.H., and Yadav, J.S. 2004. Development of a single-tube, cell lysis-based, genus-specific PCR method for rapid identification of mycobacteria: optimization of cell lysis, PCR primers and conditions, and restriction pattern analysis. J. Clin. Microbiol. 42(1): 453-457. doi:10.1128/JCM.42.1.453-457.2004. PMID: 14715804.

LeChevallier, M.W., Schulz, W., and Lee, R.G. 1991. Bacterial nutrients in drinking water. Appl. Environ. Microbiol. 57(3): 857862. PMID:2039235.

Le Dantec, C., Duguet, J.P., Montiel, A., Dumoutier, N., Dubrou, S., and Vincent, V. 2002a. Chlorine disinfection of atypical mycobacteria isolated from a water distribution system. Appl. Environ. Microbiol. 68(3): 1025-1032. doi:10.1128/AEM.68.3. 1025-1032.2002. PMID:11872446.

Le Dantec, C., Duguet, J.P., Montiel, A., Dumoutier, N., Dubrou, S., and Vincent, V. 2002b. Occurrence of mycobacteria in water treatment lines and in water distribution systems. Appl. Environ. Microbiol. 68(11): 5318-5325. doi:10.1128/AEM.68.11.53185325.2002. PMID: 12406720.

Manuel, C.M., Nunes, O.C., and Melo, L.F. 2007. Dynamics of drinking water biofilm in flow/non-flow conditions. Water Res. 41(3): 551-562. doi:10.1016/j.watres.2006.11.007. PMID: 17184812

Martiny, A.C., Jorgensen, T.M., Albrechtsen, H.J., Arvin, E., and Molin, S. 2003. Long-term succession of structure and diversity of a biofilm formed in a model drinking water distribution system. Appl. Environ. Microbiol. 69(11): 6899-6907. doi:10.1128/AEM. 69.11.6899-6907.2003. PMID:14602654.

Neonakis, I.K., Gitti, Z., Kontos, F., Baritaki, S., Petinaki, E., Baritaki, M., et al. 2010. Mycobacterium arupense pulmonary infection: antibiotic resistance and restriction fragment length polymorphism analysis. Indian J. Med. Microbiol. 28(2): 173-176. doi:10.4103/0255-0857.62502. PMID:20404471.

Regan, J.M., Harrington, G.W., and Noguera, D.R. 2002. Ammoniaand nitrite-oxidizing bacterial communities in a pilot-scale chloraminated drinking water distribution system. Appl. Environ. Microbiol. 68(1): 73-81. doi:10.1128/AEM.68.1.73-81.2002. PMID:11772611.

Reynolds, K.A., Mena, K.D., and Gerba, C.P. 2008. Risk of waterborne illness via drinking water in the United States. Rev. Environ. Contam. Toxicol. 192: 117-158. PMID:18020305.

Saeki, S., Matsuse, H., Shimoda, T., Soejima, Y., Ohno, H., and Kohno, S. 2004. A case of pulmonary Mycobacterium gordonae infection with pleural effusion. Nihon Kokyuki Gakkai Zasshi, 42(1): 103-107. PMID:14768374.[In Japanese.]

Schmeisser, C., Stockigt, C., Raasch, C., Wingender, J., Timmis, K. N., Wenderoth, D.F., et al. 2003. Metagenome survey of biofilms 
in drinking-water networks. Appl. Environ. Microbiol. 69(12): 7298-7309. doi:10.1128/AEM.69.12.7298-7309.2003. PMID: 14660379.

Schramm, A., de Beer, D., Wagner, M., and Amann, R. 1998. Identification and activities in situ of Nitrosospira and Nitrospira spp. as dominant populations in a nitrifying fluidized bed reactor. Appl. Environ. Microbiol. 64(9): 3480-3485. PMID:9726900.

September, S.M., Brozel, V.S., and Venter, S.N. 2004. Diversity of nontuberculoid Mycobacterium species in biofilms of urban and semiurban drinking water distribution systems. Appl. Environ. Microbiol. 70(12): 7571-7573. doi:10.1128/AEM.70.12.75717573.2004. PMID:15574964.

Singleton, D.R., Furlong, M.A., Rathburn, S.L., and Whitman, W.B. 2001. Quantitative comparisons of $16 \mathrm{~S}$ rRNA gene sequence libraries from environmental samples. Appl. Environ. Microbiol. 67(9): 4374-4376. doi:10.1128/AEM.67.9.4374-4376.2001. PMID:11526051.

Slany, M., Svobodova, J., Ettlova, A., Slana, I., Mrlik, V., and Pavlik, I. 2010. Mycobacterium arupense among the isolates of nontuberculous mycobacteria from human, animal and environmental samples. Vet. Med. (Praha), 55(8): 369-376.

Szewzyk, U., Szewzyk, R., Manz, W., and Schleifer, K.H. 2000. Microbiological safety of drinking water. Annu. Rev. Microbiol. 54: 81-127. PMID:11018125.

Tachikawa, M., Tezuka, M., Morita, M., Isogai, K., and Okada, S. 2005. Evaluation of some halogen biocides using a microbial biofilm system. Water Res. 39(17): 4126-4132. doi:10.1016/j. watres.2005.07.039. PMID:16169570.

Tsai, T.F., Lai, C.C., Tsai, I.C., Chang, C.H., Hsiao, C.H., and Hsueh, P.R. 2008. Tenosynovitis caused by Mycobacterium arupense in a patient with diabetes mellitus. Clin. Infect. Dis. 47(6): 861-863. doi:10.1086/591281. PMID:18713040.

Vaerewijck, M.J., Huys, G., Palomino, J.C., Swings, J., and Portaels, F. 2005. Mycobacteria in drinking water distribution systems: ecology and significance for human health. FEMS Microbiol. Rev. 29(5): 911-934. doi:10.1016/j.femsre.2005.02.001. PMID: 16219512

van der Kooij, D. 1999. Potential for biofilm development in drinking water distribution systems. J. Appl. Microbiol. 85(Suppl. 1): 39S44S. PMID:21182691.

Volk, C.J., and LeChevallier, M.W. 1999. Impacts of the reduction of nutrient levels on bacterial water quality in distribution systems. Appl. Environ. Microbiol. 65(11): 4957-4966. PMID:10543809.

White, D.C., Sutton, S.D., and Ringelberg, D.B. 1996. The genus Sphingomonas: physiology and ecology. Curr. Opin. Biotechnol. 7(3): 301-306. doi:10.1016/S0958-1669(96)80034-6. PMID: 8785434.

White, C., Tancos, M., and Lytle, D.A. 2011. Microbial community profile of a lead service line removed from a drinking water distribution system. Appl. Environ. Microbiol. 77(15): 55575561. doi:10.1128/AEM.02446-10. PMID:21652741.

Williams, M.M., Domingo, J.W.S., Meckes, M.C., Kelty, C.A., and Rochon, H.S. 2004. Phylogenetic diversity of drinking water bacteria in a distribution system simulator. J. Appl. Microbiol. 96(5): 954-964. doi:10.1111/j.1365-2672.2004.02229.x. PMID: 15078511.

World Health Organization. 2006. Pathogenic mycobacteria in water - a guide to public health consequences, monitoring and management. Edited by S. Pedley, J. Bartram, G. Rees, A. Dufour, and J. Cotruvo. IWA Publishing, London, UK. 